(C) 2020 by the Arizona Board of Regents on behalf of the University of Arizona. This is an Open Access article, distributed under the terms of the Creative Commons Attribution licence (http://creativecommons. org/licenses/by/4.0/), which permits unrestricted re-use, distribution, and reproduction in any medium, provided the original work is properly cited.

\title{
RADIOCARBON DATING OF SMALL-SIZED FORAMINIFER SAMPLES: INSIGHTS INTO MARINE SEDIMENT MIXING
}

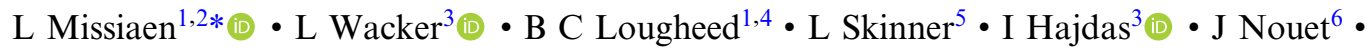 \\ S Pichat ${ }^{1,7,8} \cdot$ C Waelbroeck $^{1}$ \\ ${ }^{1}$ Laboratoire des Sciences du Climat et de l'Environnement, LSCE/IPSL, CEA-CNRS-UVSQ-Université Paris-Saclay, \\ F-91198 Gif-sur-Yvette, France \\ ${ }^{2}$ Climate Change Research Centre, University of New South Wales, Sydney, Australia \\ ${ }^{3}$ Laboratory of Ion Beam Physics, ETH Zürich, 8093 Zürich, Switzerland \\ ${ }^{4}$ Department of Earth Sciences, Uppsala University, Uppsala, Sweden \\ ${ }^{5}$ Godwin Laboratory for Palaeoclimate Research, Department of Earth Sciences, University of Cambridge, Cambridge \\ CB2 3EQ, United Kingdom \\ ${ }^{6}$ Université Paris Sud - Paris Saclay, UMR-CNRS GEOPS 8148, Bât. 504, Rue du Belvédère, 91405 Orsay, France \\ ${ }^{7}$ Université de Lyon, ENS de Lyon, Laboratoire de Géologie de Lyon (LGL-TPE), F-69007 Lyon, France \\ ${ }^{8}$ Climate Geochemistry Department, Max Planck Institute for Chemistry, Mainz, Germany
}

\begin{abstract}
Radiocarbon $\left({ }^{14} \mathrm{C}\right)$ can be used to build absolute chronologies and reconstruct ocean ventilation over the last $40 \mathrm{ka}$. Sample size requirements have restricted ${ }^{14} \mathrm{C}$ measurements in marine cores with low foraminifer content, impeding ${ }^{14} \mathrm{C}$-based studies focused on abrupt climate events. Recent developments have demonstrated that small-sized foraminifer samples can now be dated using a gas introduction system at the cost of a small decrease in precision. We explore the potential of gas measurements on benthic and planktonic foraminifers from core SU90-08 $\left(43^{\circ} 03^{\prime} 1^{\prime \prime} \mathrm{N}, 30^{\circ} 02^{\prime} 5^{\prime \prime} \mathrm{W}, 3080 \mathrm{~m}\right)$. Gas measurements are accurate, reproducible within $2 \sigma$ uncertainty and comparable to graphite measurements. Both techniques yield negative ${ }^{14} \mathrm{C}$ benthic-planktonic (B-P) age-offsets after Heinrich event 1 . We argue that negative B-P ages result from bioturbation and changes in foraminifer abundances, with the chance of negative B-P especially increased when the ${ }^{14} \mathrm{C}$ age gradient between the deep and surface waters is decreased. Small-sized ${ }^{14} \mathrm{C}$ measurements seem to capture the variance of the foraminifera age distribution, revealing the active mixing in those archives. Sediment deposition and mixing effects possibly pose a greater obstacle for past ${ }^{14} \mathrm{C}$-based dating and ocean ventilation reconstructions than the measurement precision itself, particularly in relatively low sedimentation rate settings.
\end{abstract}

KEYWORDS: Atlantic Ocean, bioturbation, foraminifera, MICADAS.

\section{INTRODUCTION}

Radiocarbon $\left({ }^{14} \mathrm{C}\right)$ is widely used by paleoceanographers to derive age-depth relationships for marine sediments over the last $50 \mathrm{ka}$. Usually, a sample of $\sim 1-3 \mathrm{mg}$ of monospecific planktonic foraminifers is ${ }^{14} \mathrm{C}$ dated by accelerator mass spectrometry (AMS). The raw ${ }^{14} \mathrm{C}$ age is then converted into a calendar age, accounting for disequilibrium with respect to the atmosphere ("reservoir age offsets"), and atmospheric ${ }^{14} \mathrm{C}$ content variations (e.g., Marine and IntCal13, Reimer et al. 2013).

Furthermore, ${ }^{14} \mathrm{C}$ is only produced in the upper atmosphere and introduced into the ocean via air-sea gas exchange, after which it gradually decays in the ocean interior, allowing ${ }^{14} \mathrm{C}$ to be used to trace past carbon cycle evolution and to reconstruct past water mass circulation history. Indeed, by determining the ${ }^{14} \mathrm{C}$ activity of benthic foraminifer samples of independently known calendar age (and assuming knowledge of the deep-water's initial ocean-atmosphere disequilibrium), one can reconstruct past ocean "ventilation ages," in other words, assess the time elapsed since the deep-water in question was last isolated from the surface

\footnotetext{
*Corresponding author. Email: 1.missiaen@unsw.edu.au
} 
(e.g. Broecker et al. 1984; Broecker et al. 1990; Skinner and Shackleton 2004; Thornalley et al. 2015). However, strictly speaking, ${ }^{14} \mathrm{C}$ ventilation metrics do not provide an unambiguous measure of transport timescales, but rather reflect the extent of disequilibrium between deep-water at a location in the ocean versus a chosen reference point, which will typically incorporate the effects of air-sea gas exchange efficiency, water sourcing and mixing as well as transport. Perhaps the most useful reference for marine ${ }^{14} \mathrm{C}$ is the contemporary atmosphere, whose ${ }^{14} \mathrm{C}$ activity varies over time (e.g. Reimer et al. 2013), due to a combination of variable ${ }^{14} \mathrm{C}$ production rates (e.g. Muscheler et al. 2004, 2005), and a changing carbon cycle. Benthic-atmosphere (B-atm) ${ }^{14} \mathrm{C}$ age differences represent one such atmospherereferenced marine ${ }^{14} \mathrm{C}$ ventilation metric, all of which are equivalent in the sense that they reflect isotopic disequilibrium (e.g. Soulet et al. (2016), and all of which require that the studied samples can be independently attributed calendar ages (e.g. Adkins et al. 1998; Skinner et al. 2014; Chen et al. 2015). Clearly, a key challenge for the reconstruction of any such ${ }^{14} \mathrm{C}$ ventilation metric is the accuracy and precision of calendar age assignments. For the reconstruction of "projection ages" (Adkins 1997), which aim to represent the (calendar) years elapsed since the deep-water in question was last at the surface, it is also necessary to know a priori the relative contributions of different surface water sources to the deep-water in question, as well as their initial ${ }^{14} \mathrm{C}$ disequilibrium versus the atmosphere. ${ }^{14} \mathrm{C}$ age offsets between contemporary benthic and planktonic foraminifera (Broecker et al. 1984) represent a widely used ${ }^{14} \mathrm{C}$ ventilation metric that does not rely on independent calendar age determination, or any other measurements. However, B-P ages represent the ${ }^{14} \mathrm{C}$ age difference between deep and surface water at the same location, and therefore ignore the potential variations in source-water ${ }^{14} \mathrm{C}$ signature related to either a shift of deep-water formation areas or a change in surface reservoir ages at the source region.

Despite the challenges related to each method highlighted above, the B-atm, B-P and projection ages have brought some constraints on past circulation changes across the millennial scale climate events of the last deglaciation (Robinson et al. 2005; Skinner et al. 2014; Chen et al. 2015). A current limitation in the use of ${ }^{14} \mathrm{C}$ in palaeoceanography is that a relatively large amount of carbonate material (typically $1-3 \mathrm{mg}$ ) is required to generate a graphite target and ultimately a ${ }^{14} \mathrm{C}$ date. For marine samples, it generally involves picking hundreds of foraminifer specimens for a single ${ }^{14} \mathrm{C}$ date. Overcoming this sample size limitation would permit the generation of higher resolution ${ }^{14} \mathrm{C}$ records in regions characterized by a low foraminifer abundance (e.g. at high latitudes) and thus, ${ }^{14} \mathrm{C}$ data within Heinrich layers where the amount of foraminifer specimens is often extremely limited (in particular for benthic species). At the same time smaller sample size might also introduce a bias by sampling smaller portion of the foraminifer population.

In the past decade, efforts have been made to lower the sample size for conventional graphite targets, for example by adjusting the graphitization reaction parameters, e.g. improving the pre-treatment and performance of the catalyst powder (Freeman et al. 2016) or changing the reaction volume (Shah Walter et al. 2016) or temperature (Santos et al. 2007). As a result, the typical sample size for conventional graphite target analysis has dropped from above $10 \mathrm{mg}$ to $3 \mathrm{mg}$ of $\mathrm{CaCO}_{3}$ for routine analysis in most AMS facilities, though samples as small as $1 \mathrm{mg} \mathrm{CaCO}_{3}$ can be run (Freeman et al. 2016). New designs such as the Mini Carbon Dating System (MICADAS) allow the analysis of graphite targets of less than $1 \mathrm{mg} \mathrm{CaCO}_{3}$ (e.g. Gottschalk et al. 2018). Besides, the MICADAS device enables the analysis of $\mathrm{CO}_{2}$ targets instead of graphite targets. This gas-inlet technology has two major benefits: (i) the sample size can be further reduced 
(the system cannot proceed with sample larger than $1 \mathrm{mg} \mathrm{CaCO}_{3}$ ); (ii) the measurement is performed online, without the graphitization step resulting in a substantial reduction of sample preparation cost and time.

The possibility of analyzing ultra-small foraminiferal samples $\left(<0.5 \mathrm{mg} \mathrm{CaCO}_{3}\right)$ (Lougheed et al. 2012; Wacker et al. 2013a) and even single foraminifer $\left(<0.1 \mathrm{mg} \mathrm{CaCO}_{3}\right)$ (Wacker et al. 2013b; Lougheed et al. 2018) has been demonstrated but for age determination sample mass should ideally be larger than $40 \mu \mathrm{g} \mathrm{C}(\sim 0.3 \mathrm{mg} \mathrm{CaCO})$ and should contain a sufficient number of individuals to reliably represent the sediment level analyzed. Gottschalk et al. (2018) showed that gas ${ }^{14} \mathrm{C}$ analysis of small-sized $\left(\sim 0.3-0.6 \mathrm{mg} \mathrm{CaCO}_{3}\right)$ foraminifera samples give accurate results with only a slight precision decrease (a few tens of years on ${ }^{14} \mathrm{C}$ scale) compared to graphite target AMS measurements. Better precision can be achieved by replicating the measurements in order to extract a mean age and the corresponding uncertainty. Despite the apparent advantages, ${ }^{14} \mathrm{C}$ gas measurements have yet to be widely used for paleoceanographic studies, and measurements are still needed to further test the accuracy and reproducibility of small-sized foraminifer sample ${ }^{14} \mathrm{C}$ gas measurements in the marine sedimentary context.

Here we report new benthic and planktonic gas ${ }^{14} \mathrm{C}$ measurements from North-Atlantic core

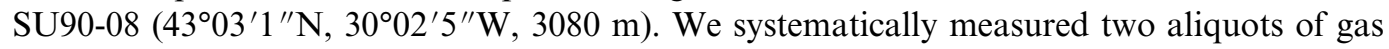
samples and compared those results with conventional graphite measurements $(n=10)$. The goal of this study is to (i) further test the reproducibility and accuracy of small-sized gas introduction ${ }^{14} \mathrm{C}$ measurements on deep-sea foraminifer samples using the MICADAS setup and (ii) assess the benefits of these measurements for the study of past ocean ventilation, as compared to graphite-based AMS measurements.

\section{STUDY SITE AND METHODOLOGY}

\section{Sample Material}

Sediment core SU90-08 was retrieved in 1990 by the French R/V Suroit during the Paleocinat cruise on the mid-Atlantic ridge flank, in the western Atlantic basin $\left(43^{\circ} 03^{\prime} 1^{\prime \prime} \mathrm{N}, 30^{\circ} 02^{\prime} 5^{\prime \prime} \mathrm{W}\right.$, $3080 \mathrm{~m}$ ). Based on the planktonic $\delta^{18} \mathrm{O}$ record, the sediment available have been shown to cover about $260 \mathrm{kyr}$ of climate history and the average sedimentation rate is $4.6 \mathrm{~cm} / \mathrm{kyr}$ (Grousset et al. 1993; Bout-Roumazeilles et al. 1999). The sediment is mainly composed of carbonates (foraminifera ooze and nanofossils) interbedded with clay layers (Bout-Roumazeilles et al. 1999). Levels showing accumulation of coarse detrital material from iceberg discharges, Ice Rafted Debris (IRDs), attributed to Heinrich events 1, 2 and 4 have been identified in the first $250 \mathrm{~cm}$ of the core corresponding to the last $40 \mathrm{ka}$ (Vidal et al. 1997; BoutRoumazeilles et al. 1999; Kissel 2005; Missiaen et al. 2019). Bulk wet sediments were oven-dried $\left(50^{\circ} \mathrm{C}\right)$ for about $48 \mathrm{hr}$ and then water-sieved at $150 \mu \mathrm{m}$ mesh to remove fine particles. The $>150 \mu \mathrm{m}$ fraction was rinsed with de-ionized water and oven-dried $\left(50^{\circ} \mathrm{C}\right)$ for about $24 \mathrm{hr}$. Planktonic foraminiferal assemblages were determined downcore by counting on average 423 specimens on unbiased splits of the fraction $>150 \mu \mathrm{m}$. The most abundant species are $G$. bulloides ( $26 \%$ on average over the record) and $N$. pachyderma (sinistral, $29 \%$ on average over the record) (Figure 1). Benthic and planktonic foraminifers were handpicked from respectively 28 and 29 sediment slices covering the last $25 \mathrm{kyr}$. The low availability of benthic foraminifers, especially within the Heinrich layers, motivated the gas introduction system analyses. Because of the small amount of benthic foraminifer available in the samples and because the represented genus of benthic foraminifer changes downcore, 


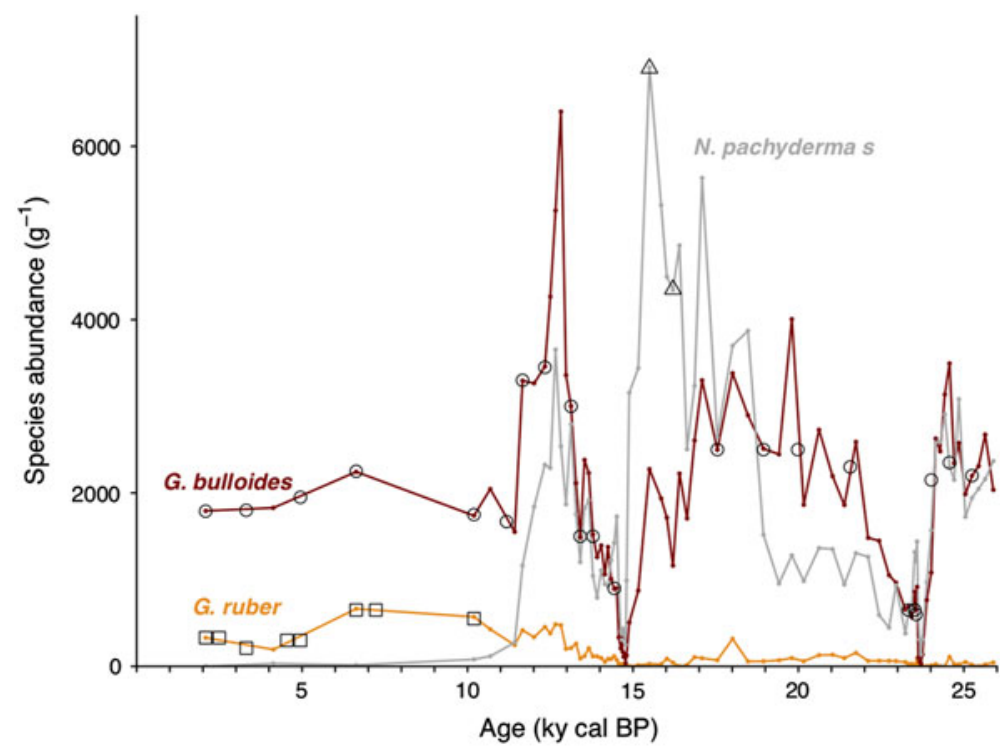

Figure 1 Downcore evolution of planktonic foraminifer abundances: The red line represents the evolution of $G$. bulloides absolute abundance, the gray line, the evolution of $N$. pachyderma (sinistral) abundance, the orange line, the evolution of $G$. ruber abundance. The black empty symbols represent the sampled levels for gas ${ }^{14} \mathrm{C}$ analysis, the black squares represent the levels sampled for graphite analysis. Age model from Missiaen et al. (2019). (Please see electronic version for color figures.)

mixed benthic species were picked (excluding porcelaneous species (see Magana et al. 2010), and agglutinate specimens that include sedimentary material). To minimize the bioturbation effect on planktonic ${ }^{14} \mathrm{C}$ dates, we only selected specimens amongst the most abundant species: G. bulloides and N. pachyderma sinistral for 27 and 2 sediment slices, respectively (see Figure 1). Single species samples of $G$. ruber $(\mathrm{n}=8)$ were also prepared to examine ${ }^{14} \mathrm{C}$ age difference between coexisting species (e.g. Broecker et al. 1988; Mekik 2014). To assess the value of the ${ }^{14} \mathrm{C}$ background on the foraminifer material so-called the foraminifer blank, we also picked samples of ${ }^{14} \mathrm{C}$-dead foraminifers from the core bottom $(>260 \mathrm{kyr}$ cal BP). The age obtained on this ${ }^{14} \mathrm{C}$-dead foraminifer samples was then used to perform the blank correction.

The foraminifers selected for gas measurements were cleaned with de-ionized water. No oxidative treatment (e.g. $\mathrm{H}_{2} \mathrm{O}_{2}$ ) was applied to preserve the shell integrity and avoid potential contamination with modern atmospheric $\mathrm{CO}_{2}$. Under the binocular microscope, the selected foraminifers appeared intact and did not display dissolution features or extraneous sediment/residue attached to the outer shell. Because the effect of contamination (either by modern/radiocarbon rich or old/radiocarbon poor content) increases as the sample size is reduced (Gottschalk et al. 2018), we maintained a constant sample size for each method $\left(0.97 \pm 0.29\left[\begin{array}{ll}1 & \sigma\end{array}\right] \mathrm{mg} \mathrm{CaCO}_{3}\right.$ on average). After picking and weighing, each sample was put in septum sealed glass vials and flushed with helium at $50 \mathrm{~mL} / \mathrm{min}$ for $5 \mathrm{~min}$ in order to remove the modern $\mathrm{CO}_{2}$ from the vials. 
The ${ }^{14} \mathrm{C}$ analysis was carried out at the Laboratory of Ion Beam Physics at ETH Zürich using an Ionplus carbonate handling system (Wacker et al. 2013a) coupled to MICADAS AMS (Synal et al. 2007) with a helium stripping system, which leads to better signal on small samples.

Twelve ${ }^{14} \mathrm{C}$ gas measurements were compared with standard graphite analysis for the same depths. Graphite measurements were performed either at ETH Zürich $(n=7)$ or Chrono Center, Queens University Belfast $(\mathrm{n}=4)$, following a standard method of $\mathrm{CO}_{2}$ reduction in the presence of hydrogen over iron catalyst (Vogel et al. 1984). The graphite sample size was $0.28 \pm 0.05(1 \sigma) \mathrm{mg} \mathrm{C}$ for ETH Zürich and $0.41 \pm 0.15(1 \sigma) \mathrm{mg} C$ for Chrono Centre Belfast.

\section{Gas Measurements Reproducibility and Accuracy}

In order to assess the reproducibility of our gas measurements, we systematically replicated our planktonic and benthic ${ }^{14} \mathrm{C}$ measurements when enough material was available for the deglacial section of SU90-08. Along with the samples, standard material was also measured to assess the accuracy of the measurements and process the ${ }^{14} \mathrm{C}$ data following the normalization to standard method. Multiple measurements of the IAEA standards C2 (travertine, consensus $\mathrm{F}^{14} \mathrm{C}$ value $=0.4114 \pm 0.0003, \delta^{13} \mathrm{C}=-8.25 \pm 0.31 \%$ o VPDB; Rozanski et al. 1992) and $\mathrm{C} 1$ (marble, consensus $\mathrm{F}{ }^{14} \mathrm{C}=0.0000 \pm 0.0002, \delta^{13} \mathrm{C}=-2.42 \pm 0.33 \%$ VPDB; Rozanski et al. 1992) and CSTD standard (coral, $F{ }^{14} \mathrm{C}=0.9445 \pm 0.0018$; Gao et al. 2014) were performed. For the sake of consistent sample-standard comparison, the standard and sample sizes were equivalent $(\sim 1 \mathrm{mg})$. Additionally, the National Institute of Standards and Technology (NIST) standard oxalic acid II (OxII) was also analyzed directly as $\mathrm{CO}_{2}$ from a purchased gas bottle (Ionplus, Switzerland). The data processing was performed with the software BATS (version 4.20, Wacker et al. 2010) and includes the selection of the current plateau, correction for isotopic fractionation from the AMS using $\delta^{13} \mathrm{C}$, and the blank contribution using the foraminifer blanks. Uncertainties are fully propagated for each correction.

\section{Leaching Analysis}

The online gas measurement and carbonate handling system setting allows for a weak leaching prior to the total sample dissolution (Bard et al. 2015). The samples are first acidified with $100 \mu \mathrm{L}$ of $0.02 \mathrm{~N} \mathrm{HCl}$ for at least $30 \mathrm{~min}$ at $50^{\circ} \mathrm{C}$ temperature, which dissolves $\sim 120 \mu \mathrm{g}$ of $\mathrm{CaCO}_{3}$ in each sample. The $\mathrm{CO}_{2}$ produced by the reaction is flushed into the MICADAS and analyzed as the leach fraction. Once the leaching analysis is complete, the samples are acidified with $0.1 \mathrm{~mL} 85 \%$ orthophosphoric acid $\left(\mathrm{H}_{3} \mathrm{PO}_{4}\right)$ for at least $30 \mathrm{~min}$ at $50^{\circ} \mathrm{C}$ in order to convert the remaining carbonates into $\mathrm{CO}_{2}$. The sample is then flushed into the MICADAS and analyzed as the main fraction. It is worth noting that the gas introduction system used can only handle samples of equivalent $1 \mathrm{mg} \mathrm{CaCO}_{3}$ or smaller. For the samples exceeding this size limit, an aliquot of gas corresponding to the maximum capacity was measured while the rest of the gas was discarded. On average, about $85 \pm 26(1 \sigma) \mu \mathrm{g} \mathrm{C}$ were analyzed as the main fraction of gas samples.

This technique gives the opportunity to assess the consistency of the ${ }^{14} \mathrm{C}$ signal of the inner and outer part of the foraminifera and thus to draw inferences regarding possible dissolution/ recrystallization of the shells, which would be indicated by large ${ }^{14} \mathrm{C}$ age differences between the main and leach fractions. 

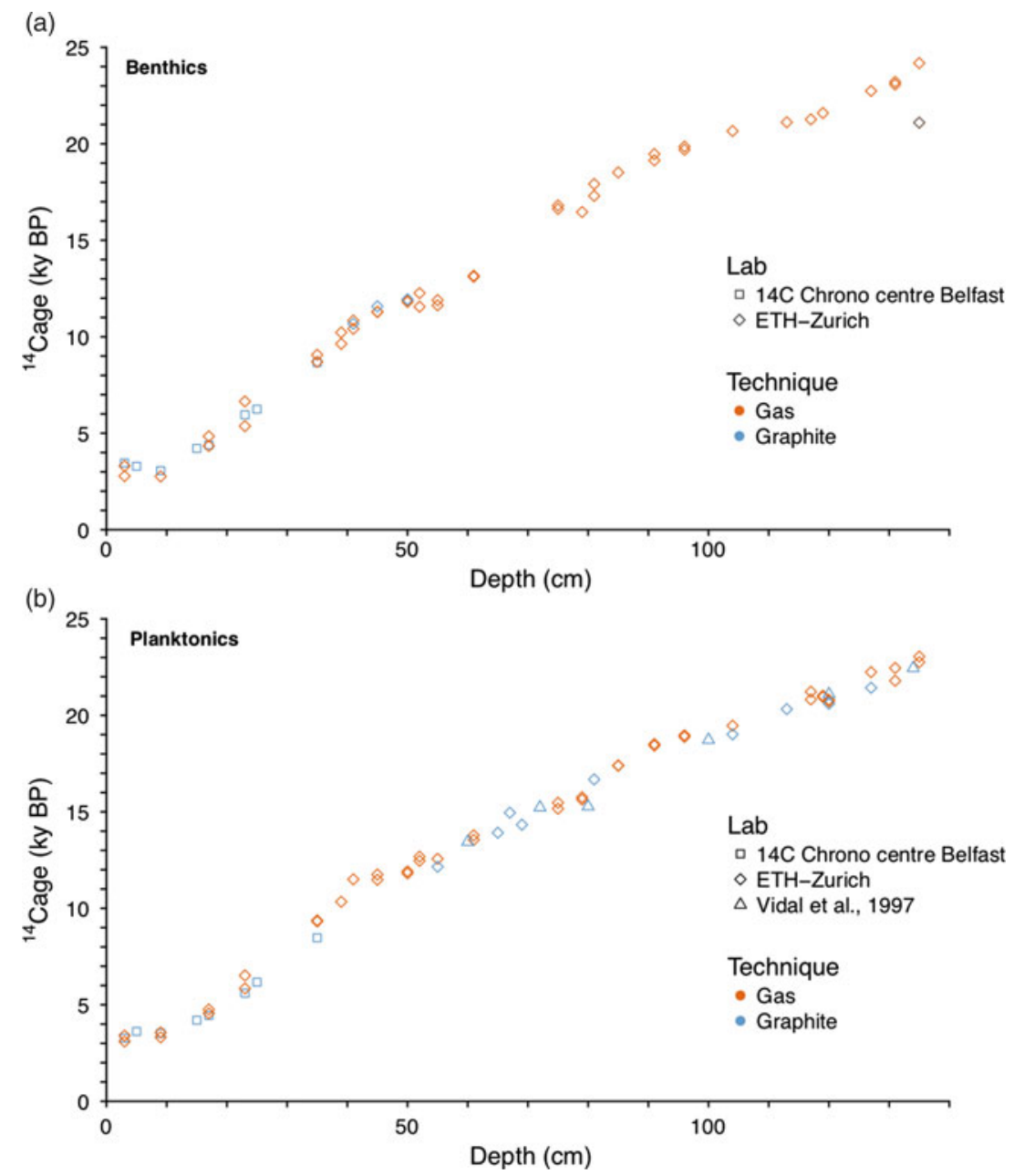

Figure $2{ }^{14} \mathrm{C}$ age-depth relationship for sediment core SU90-08: (a) benthic and (b) planktonic foraminifers. The orange symbols represent the gas measurements while the blue symbols represent the graphite measurements. The gray point of the top panel corresponds to an off-trend benthic measurement which was excluded from the subsequent interpretations.

\section{RESULTS AND DISCUSSION}

\section{Gas Measurements Evaluation}

\section{Accuracy of Gas Measurements}

Generally, the gas and graphite measurements show a consistent age-depth relationship and our new measurements are consistent with existing ${ }^{14} \mathrm{C}$ data (Vidal et al. 1997; see Figure 2). We tested the accuracy of our ${ }^{14} \mathrm{C}$ gas data by measuring standard materials IAEA-C1, IAEA-C2, coral CSTD and foraminifer blank (foraminifers older than $260 \mathrm{kyr}$ ) along with the samples. The values obtained: $\sim 458$ (coral CSTD) and 7135 (IAEA-C2) year old carbon, agree with the consensus values within the $2 \sigma$ uncertainty (Table S1) the age offsets 
having a standard deviation $(1 \sigma)$ of 55 years for CSTD coral and 136 years for IAEA-C2. Typical gas measurement background levels $\left({ }^{14} \mathrm{C}\right.$-dead IAEA-C1 and foraminifers) were $\sim 0.5 \%$ modern carbon, $(\% \mathrm{mC})(>42,000$ years equivalent $)$. Comparable levels of standard reproducibility were obtained for graphite measurements, with a slight improvement due to the larger sample sizes analyzed (see Table S1). Typical graphite background levels obtained were $\sim 0.23 \% \mathrm{mC}$ ( $>48,800$ years equivalent) of modern carbon for Belfast measurements and $\sim 0.26 \% \mathrm{mC}$ for ETH measurements ( $>47,000$ years equivalent).

\section{Reproducibility of Gas Measurements}

The reproducibility of our gas measurements on foraminifera was assessed using 19 duplicated ${ }^{14} \mathrm{C}$ gas analyses for planktonic foraminifers and 17 duplicated ${ }^{14} \mathrm{C}$ gas analyses for benthic foraminifers (Table S2). One benthic replicate at $135 \mathrm{~cm}$ was found to completely off the age trend (Figure 2) and is therefore not included in the subsequent analysis. The absolute ${ }^{14} \mathrm{C}$ age offsets between replicates have no remarkable downcore evolution (Table S2) and range between 2 and 1278 years with an average of 227 years for the planktonic foraminifera $(1 \sigma=192, \mathrm{n}=19)$ and 389 years for the benthic $(1 \sigma=320, \mathrm{n}=16)$ foraminifera. Evaluating the downcore evolution of the gas measurements reproducibility requires accounting for the evolution of the analytical uncertainties, the latter growing exponentially as the sample ${ }^{14} \mathrm{C}$ content decreases (Figure 3A). Using 10,000 Monte Carlo draws, we estimate the expected downcore reproducibility between 2 replicates $( \pm 2 \sigma)$, accounting for the downcore evolution of the analytical uncertainties and compare it to our sample reproducibility (Figure 3B). The upper part of the core $(0-30 \mathrm{~cm}$ or $3-8 \mathrm{kyr}$ i.e. 2-10 ka cal BP, see Missiaen et al. 2019) is characterized by larger observed ${ }^{14} \mathrm{C}$ age offsets between the replicates with respect to the expectation i.e. poorer reproducibility than the section below (35-135 $\mathrm{cm}$ or 10-25 ka). This sharp change in reproducibility is not synchronous with any of the abrupt climatic events (Younger Dryas [YD], Heinrich Stadial 1 or 2 [HS1-HS2 respectively]).

The poor reproducibility of measurements observed in the top $30 \mathrm{~cm}$ of SU90-08 core is likely related to greater syn-depositional or post-depositional mixing in the upper $\sim 30 \mathrm{~cm}$ of the sediment. According to the current understanding of deep-sea sediment bioturbation processes, the top most layer of the sediment, referred as the mixed layer, is uniformly mixed by benthic life (e.g. burrowing, Berger and Heath 1968; Guinasso and Schink 1975; Berger and Johnson 1978; Berger and Killingley 1982; Peng et al. 1997). Therefore, the average age of the uppermost sediment should be near-identical down to the bottom of the contemporary mixed layer, which is typically between 5 and $10 \mathrm{~cm}$ thick (Trauth et al. 1997). Indeed, we see uniform ${ }^{14} \mathrm{C}$ ages to $\sim 10 \mathrm{~cm}$ depth (levels 3,5 , and $9 \mathrm{~cm}-$ average age $3402{ }^{14} \mathrm{C}$ yr BP, $3287 \mathrm{cal} \mathrm{yr} \mathrm{BP}$ ) in our sediment core (Figure 2a,b). Below $17 \mathrm{~cm}$, we see that average ${ }^{14} \mathrm{C}$ ages corresponding to the historical layers increase incrementally with core depth. Note that the mixed layer thickness may have changed in the past according to changes in benthic life activity in relation with bottom water oxygenation and nutrient availability.

In the bottom part of the record (i.e. below $\sim 30 \mathrm{~cm}$, or before $10 \mathrm{ka}$ cal BP), the observed reproducibility roughly fits to the expectation. Besides, the planktonic reproducibility appears to be much better than its benthic counterpart (Figure 3B), in contrast to what has been reported in Gottschalk et al. (2018). It is important to stress that the benthic measurements were conducted on mixed species, which probably contribute to the poorer reproducibility of benthic measurements compared to single species planktonic measurements as infaunal and 

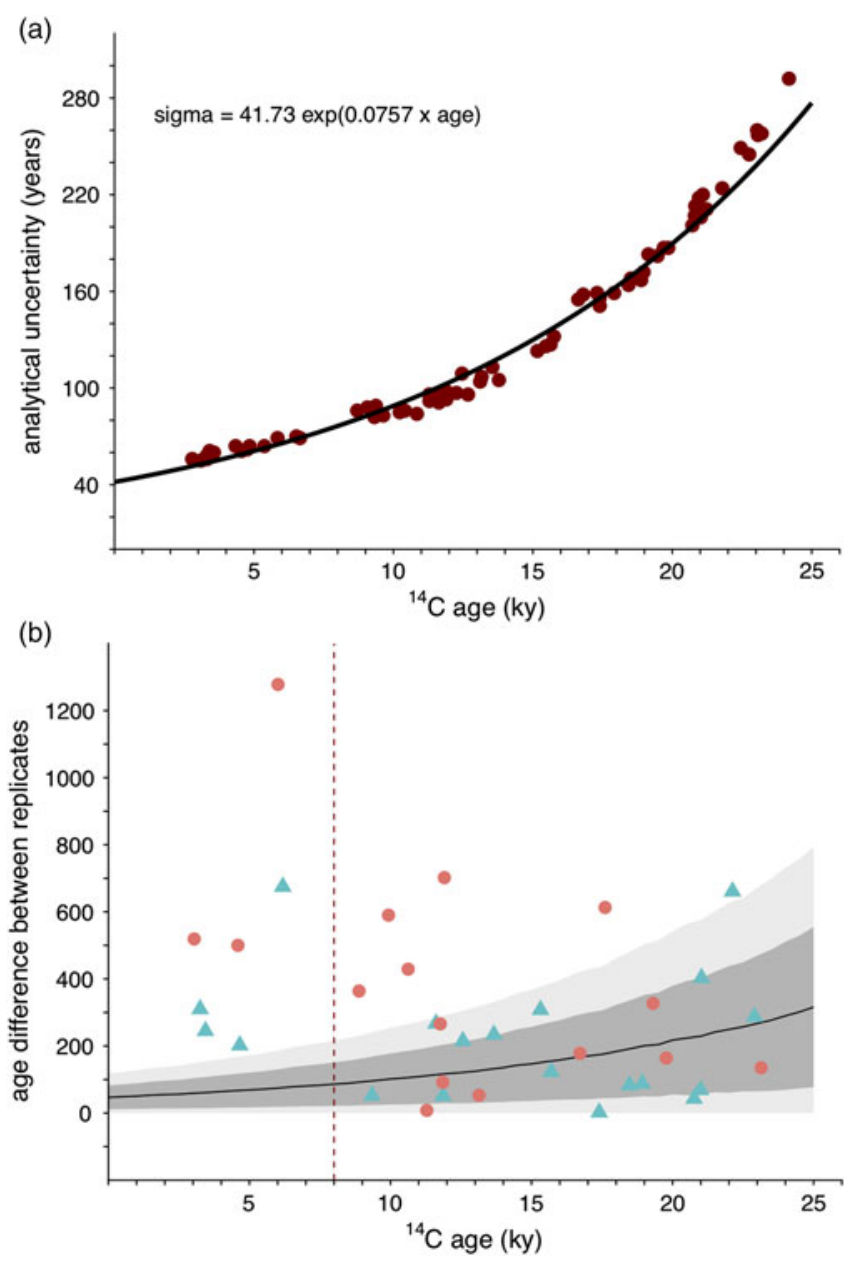

Figure 3 Reproducibility of the benthic and planktonic ${ }^{14} \mathrm{C}$ gas measurements: (a) Evolution of the analytical uncertainty with measured ${ }^{14} \mathrm{C}$ age (red dots-benthic and planktonic together). The black line represents the exponential function fitting the measured analytical uncertainty. (b) Comparison between the expected age offset between two replicates of the same age when taking into account the analytical uncertainty only (black line and gray error envelopes) and the observed reproducibility for SU90-08 benthic (red dots) and planktonic (blue triangles) gas ${ }^{14} \mathrm{C}$ dataset. The expected reproducibility is obtained from Monte Carlo draws of paired samples of a given ${ }^{14} \mathrm{C}$ age. For each given sample ${ }^{14} \mathrm{C}$ age, we randomly draw 10,000 pairs of samples within a gaussian distribution defined by the considered ${ }^{14} \mathrm{C}$ age and the analytical uncertainty (Figure 1A). We then extract the mean age offset (black line), its variance $(2 \sigma$-light gray envelope) and its standard deviation ( $1 \sigma-$ dark gray envelope). The data is plotted against measured or theoretical ${ }^{14} \mathrm{C}$ age. The red vertical dashed line highlights the very poor reproducibility observed in the upper $30 \mathrm{~cm}$ of the core (see text for details). For the samples falling out of the expected reproducibility shade, the poor reproducibility cannot be solely explained by the analytical uncertainty on the measurements. Instead, we argue that these samples have been affected by other processes, such as variations of the benthic species assemblages or bioturbation. 
epifaunal species of a given sample have been suggested to exhibit different ${ }^{14} \mathrm{C}$ signatures (Rafter et al. 2018). Setting aside the top $30 \mathrm{~cm}$ of the record, $94 \%$ of the planktonic measurements fall in the expected $2 \sigma$ reproducibility range (roughly $65 \%, 1 \sigma$ ). On the other hand, below $35 \mathrm{~cm}$, around $62 \%$ of the benthic ${ }^{14} \mathrm{C}$ gas measurements fall in the expected $2 \sigma$ reproducibility range (roughly $46 \%, 1 \sigma)$. Namely, early Holocene and HS1 benthic samples are not so well replicated, while glacial benthic ${ }^{14} \mathrm{C}$ replicates compare well.

\section{Comparison of Gas and Graphite Measurements}

We compare gas and graphite measurements on both $G$. bulloides and mixed benthic foraminifers (Figure 4AB), and we compare gas measurements on G. bulloides to graphite measurements on G.ruber (Figure 4C). We observe no discernable difference between the gas and graphite measurements, with a coefficient of determination $\left(\mathrm{R}^{2}\right)$ for all the gas and graphite measurements above 0.99 (Figure S1). In detail, for each level where duplicated gas measurements and a graphite measurement are available, we assess the reproducibility of the measurements by calculating the standard deviation of the multiple ${ }^{14} \mathrm{C}$ dates (Table S3). On average, this standard deviation is $228 \mathrm{yr} \pm 199 \mathrm{yr}(1 \sigma)$ for mixed benthic foraminifera, $322 \mathrm{yr} \pm 194 \mathrm{yr}(1 \sigma)$ for G.bulloides, and $286 \mathrm{yr} \pm 188 \mathrm{yr}(1 \sigma)$ for G.bulloides and G.ruber.

The graphite measurements generally agree with at least one gas replicate within $2 \sigma$ uncertainty or correspond to the average of the gas replicates (Figure 4), except for 3 analyzed levels: $23 \mathrm{~cm}$ (benthic and planktonic), $35 \mathrm{~cm}$ (planktonic) and $127 \mathrm{~cm}$ (planktonic). We note that some levels display poor reproducibility between the gas samples, especially at $23 \mathrm{~cm}$, perhaps due to the lower sediment accumulation rate in the upper $30 \mathrm{~cm}$ of the core. Excluding those levels from the dataset, the standard deviation of gas and graphite measurements for a given depth level is on average $199 \mathrm{yr} \pm 97 \mathrm{yr}$ for mixed benthic foraminifera, 194 $\mathrm{yr} \pm 118 \mathrm{yr}$ for G.bulloides, and $188 \mathrm{yr} \pm 15 \mathrm{yr}$ for G.bulloides and G.ruber. These values are of the same order of magnitude as reported in Gottschalk et al. (2018).

We must stress that the reproducibility of gas and graphite dating methods themselves has already been assessed by comparing gas and graphite measurements carried out on reference material (see Wacker et al. 2013b). Both in the present study and in Gottschalk et al. (2018), the gas and graphite measurements also capture a different kind of variability related to the natural foraminifer population diversity, the effect of sediment mixing as well as the selection of foraminifer specimens while preparing the samples.

To summarize: (i) the standard materials analyzed along with the samples indicate that the gas measurements were accurate; (ii) the reproducibility of gas measurements younger than $10 \mathrm{ka}$ is poor, very likely because of high heterogeneity of the foraminifer populations related to sediment remobilization by in-situ bioturbation; the gas measurements replicates from 10 to $25 \mathrm{ka}$ generally agree within the $2-\sigma$ uncertainty and the overall reproducibility is comparable to what has been reported in (Gottschalk et al. 2018) except for 3 analyzed levels; (iii) the graphite measurements generally agree with at least one gas replicate within $2 \sigma$ uncertainty or correspond to the average of the gas replicates except for 3 analyzed levels. Overall, this analysis demonstrates that both methods (gas and graphite) produced consistent results on of SU90-08 samples. In what follows, we use those measurements to generate benthic-planktonic (B-P) ventilation ages. 

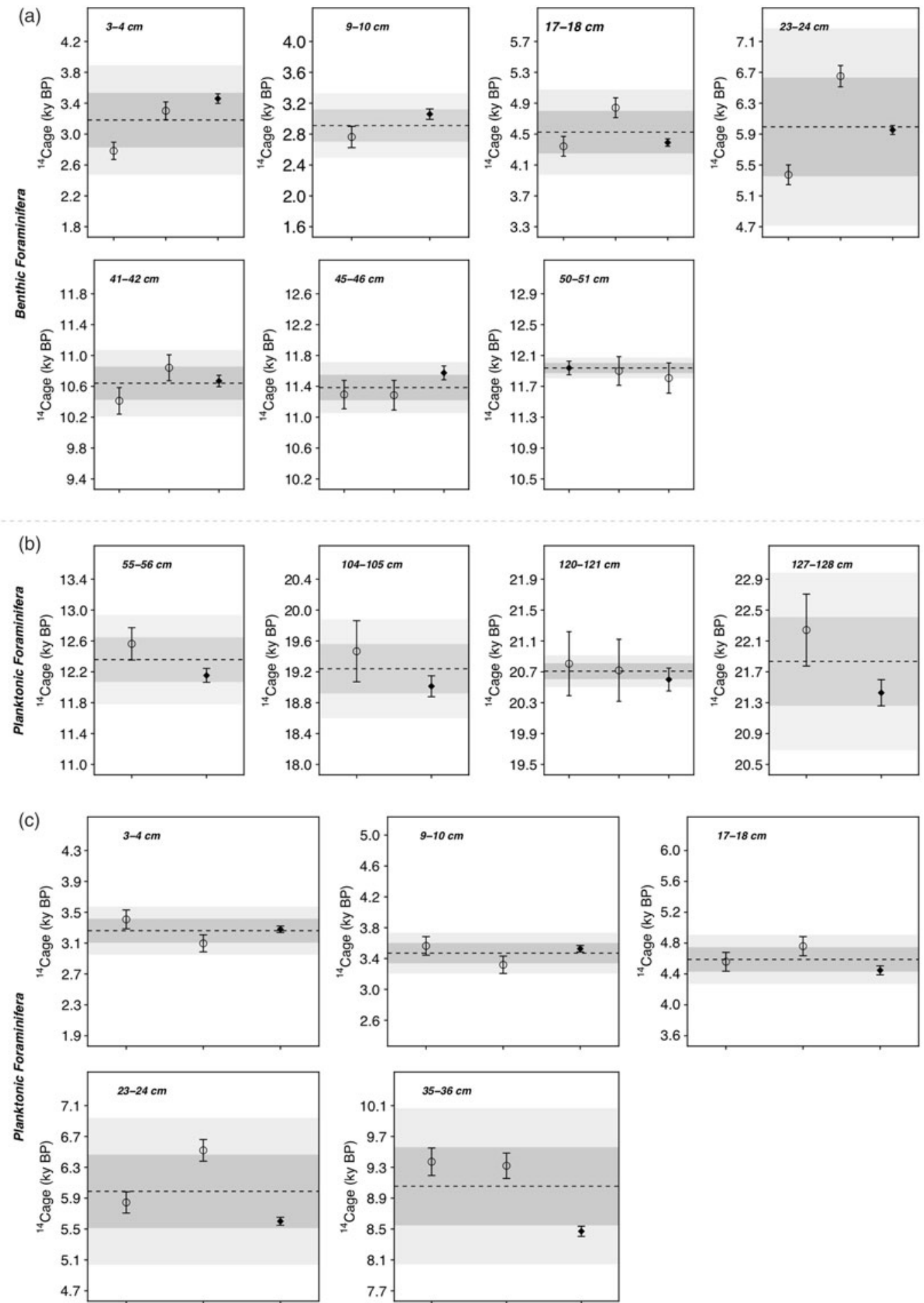

Figure 4 Comparison between gas and graphite for benthic and planktonic foraminifera. Comparison between gas and graphite measurements for (a) mixed benthic species. (b) G.bulloides and (c) different planktonic species (i.e. G.bulloides for gas measurements and G.ruber for graphite measurements). In each subplot, the gas measurements are represented by open circles, the graphite measurements by black diamonds. The $2-\sigma$ uncertainty is represented in black. The dashed line represents the mean of all measurements. The horizontal dark gray (light gray) band indicates the $1 \sigma(2 \sigma)$ uncertainty calculated from all available measurements. 

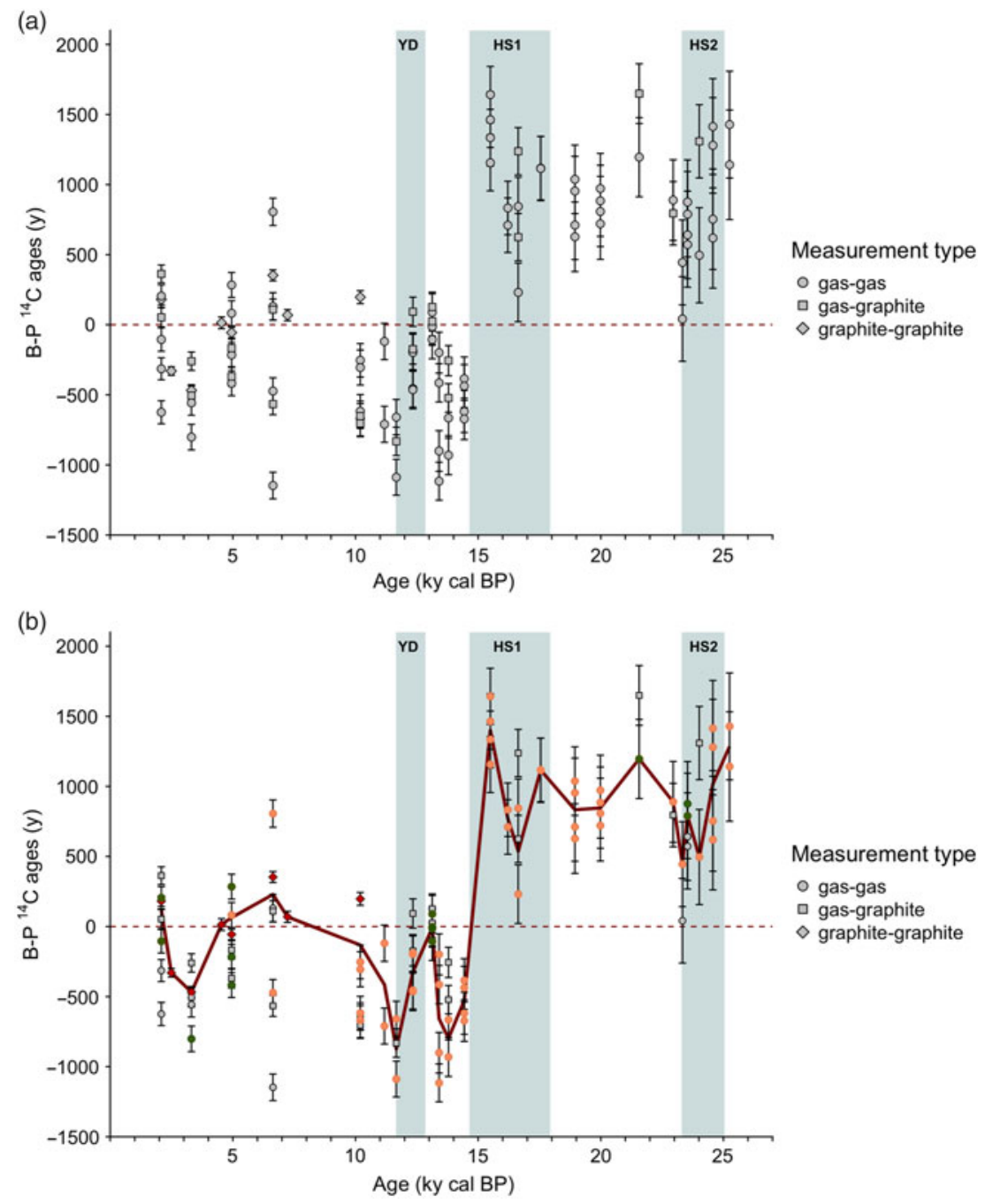

Figure 5 SU90-08 B-P ${ }^{14} \mathrm{C}$ ages time series: (a) Raw B-P ${ }^{14} \mathrm{C}$ ages obtained from all pairs of measurements with the available dataset. The symbol type indicates the measurement type: gas vs gas measurements are represented by circles, gas vs. graphite by squares and graphite vs graphite by diamonds. (b) Screened B-P ${ }^{14} \mathrm{C}$ ages time series. The red symbols correspond to graphite vs. graphite B-P pairs. The orange symbols correspond to the data that passed the leaching control (see Figure S5). The green symbols represent pairs for which one graphite measurements agrees with one benthic or planktonic gas measurement within 2- $\sigma$ uncertainty. The bold red line connects the average screened data (i.e. colored symbols).

\section{Post HS1 Negative ${ }^{14} \mathrm{C}$ B-P Ages}

We calculated the ${ }^{14} \mathrm{C}$ B-P ages for each depth level based on the gas and graphite replicated measurements (Figure 5). We observe wide ranges (up to $1000 \mathrm{yr}$ ) of ${ }^{14} \mathrm{C} \mathrm{B-P}$ ages per level as well as negative values in the top part of the record, i.e. from HS1 to the late Holocene (Figure 5A). The ${ }^{14} \mathrm{C}$ B-P ages are usually expected to be positive because the deep watermasses are expected to have been isolated from the surface for a longer time than the surface waters directly above them. Negative ${ }^{14} \mathrm{C}$ B-P ages, when occurring infrequently, 
are often discarded in paleoceanographic studies (e.g. Wan and Jian 2014). In our study, however, they represent a systematic signal over the entire upper section of core SU90-08. Therefore, they cannot be considered as outliers and need to be explained.

Negative B-P ages may arise if a process is able to affect the ${ }^{14} \mathrm{C}$ content of foraminifer samples and bias the benthic foraminifers towards younger ages or/and bias the planktonic foraminifers toward older ages, or in a situation where benthic foraminifera are living in less ${ }^{14} \mathrm{C}$ depleted waters than their planktonic counterparts. The latter situation is unlikely because modern B-P ${ }^{14} \mathrm{C}$ age gradient is positive (Key et al. 2004). Therefore, below we focus on two diagenetic processes that are able to generate negative ${ }^{14} \mathrm{C}$ B-P ages.

A first concern is that core SU90-08 is located in the vicinity of the Mid-Atlantic Ridge and in some cases post-depositional hydrothermal processes have been to affect the foraminifers ${ }^{14} \mathrm{C}$ content by circulating ${ }^{14} \mathrm{C}$-dead fluids (Marchig et al. 1984; McCarthy et al. 2011). However, we find no evidence of a positive Eu anomaly in the rare earth elements (REE) measured in SU90-08 samples, which would indicate the influence of hydrothermal processes (see Text S1 and Figure S2 for details).

A second concern is the foraminifer shell preservation. Indeed, the lysocline depth is susceptible to change through time, bringing sediments at the sediment-water interface into contact with waters in which $\mathrm{CaCO}_{3}$ tends to dissolve (Le and Shackleton 1992; Yu and Elderfield 2007). Consequently, the foraminifer shells can be partly dissolved, and potentially recrystallized with secondary calcite when pore-fluid carbonate saturation increases again, yielding an altered ${ }^{14} \mathrm{C}$ composition (Peng and Broecker 1984; Barker et al. 2007; Wycech et al. 2016). In particular, it has been observed that frosty and recrystallized shells appear older in the ${ }^{14} \mathrm{C}$ scale than translucent and well-preserved shells (Mekik 2014; Wycech et al. 2016), potentially producing negative ${ }^{14} \mathrm{C}$ B-P ages. In order to assess the dissolution/recrystallization state of our foraminifer samples, we (i) examined some specimens on scanning electron microscope (SEM) pictures (see text S2 for details) and (ii) analyzed the consistency between leach and main fraction ${ }^{14} \mathrm{C}$ measurements. Generally, the foraminifers look well preserved. In details, the benthic foraminifers analyzed do not exhibit recrystallization features (see Figure S3). By contrast, some planktonic foraminifers exhibit some secondary calcite crystals with characteristic rhombohedral shape as well as dissolution features (see Figure S3). This can be related to the more fragile shell of planktonic foraminifer, exhibiting finer outer 3D structures compared to their benthic counterparts displaying rather smooth surfaces (see Figure S3). Therefore, we cannot exclude at this stage that the planktonic foraminifera's shells have incorporated older carbon from the surrounding sediments during their dissolution and recrystallization. However, there is no obvious downcore change in the planktonic foraminifer dissolution. Thus, if dissolution and recrystallization processes could produce negative ${ }^{14} \mathrm{C}$ B-P ages, they do not obviously explain the shift between the upper part of the core (with negative ${ }^{14} \mathrm{C}$ B-P ages) and the deeper part of the core (exhibiting positive ${ }^{14} \mathrm{C}$ B-P ages).

In addition, the analysis of our gas main and leach fraction ${ }^{14} \mathrm{C}$ content can also bring information about the preservation (dissolution/recrystallization) state of the foraminifer specimens that have been analyzed for ${ }^{14} \mathrm{C}$ and that could not be pictured with SEM due to sample preparation requirements. If the leaching acid dissolves always the same amount of $\mathrm{CaCO}_{3}$, the nature of what is exactly dissolved is still unclear. It is expected that the leach fraction corresponds to the foraminifer outer shell that is directly exposed to the leaching 
acid, or possibly to coccoliths remaining at the surface of the foraminifera shells (as they can be present on the analyzed specimens; see Figure S3A [c, d, e, f]). Overall, this material has been exposed to the modern atmosphere since core retrieval and therefore, the leach fraction has usually slightly younger ${ }^{14} \mathrm{C}$ ages than the main fraction, which corresponds to the inner shells (see Figure S4). However, an altered sample (i.e. a shell that has undergone significant dissolution/recrystallization), would display an outer shell (leach fraction) generally older than the inner shell (main fraction), which can be related to the incorporation of older or even ${ }^{14} \mathrm{C}$ dead carbon content from the underlying sediment layers during dissolution/recrystallization processes, as suggested by (Broecker et al. 1984; Barker et al. 2007). Importantly, altered shells will also be characterized by a high difference between the outer part (leach fraction) and the inner part (main fraction). To distinguish potentially contaminated (e.g. by coccoliths), altered or dissolved samples we discard the samples for which the ${ }^{14} \mathrm{C}$ age difference between the main and the leach fraction largely exceeds the expectations. Assuming distinct exponential relationships between the sample ${ }^{14} \mathrm{C}$ age (i.e. content) and the analytical uncertainty for both the main fraction and the leach fraction, we estimate from 10,000 Monte Carlo draws the expected apparent ${ }^{14} \mathrm{C}$ age offset between a main and a leach fraction having supposedly the same ${ }^{14} \mathrm{C}$ age (Figure S4). Note that the analytical uncertainty of the leach fraction is larger than the one of the main fraction, for a given age because the leach fraction is of a smaller size. Besides, for our samples, the main and leach fraction are not expected to strictly have the same age due to potential contaminations of the sample. In this study we tolerate an age offset between the main and leach fraction which is up to 3 times equal to the mean expected age offset accrued by $1 \sigma$. We also rejected the samples displaying a very negative main-leach fraction offset (i.e. below the expected mean, $2 \sigma$ ) as older leach fraction is a potential indicator for recrystallization as discussed above. By following this procedure, we excluded 9-paired leach and main fraction ${ }^{14} \mathrm{C}$ gas measurements from our dataset (see Figure S4), representing less than $10 \%$ of our available gas measurements. Interestingly the benthic sample which appeared off-trend (Figure 2) did not pass the leaching test.

To conclude, we observe repeated negative ${ }^{14} \mathrm{C}$ B-P ages for the post HS1 part of SU90-08 record that cannot be simply considered as outliers. We show that those results are unlikely to correspond to hydrothermal imprint on the foraminifer ${ }^{14} \mathrm{C}$ content or be the result of dissolution/recrystallization of the foraminifer shells. Therefore, these negative ${ }^{14} \mathrm{C}$ B-P ages have to be interpreted in terms of modern and past oceanic ventilation changes, or sediment dynamics and mixing of benthic and planktonic foraminifers.

\section{Reconciling Negative B-P Ages with Ocean Ventilation}

\section{Sample Heterogeneity Highlighted by Small-Sized ${ }^{14} \mathrm{C}$ Measurements}

The comparison between gas and graphite measurements as well as the leach fraction analysis permits to screen the raw ${ }^{14} \mathrm{C}$ B-P ages. In what follows, we retain the graphite-graphite B-P ages (red on Figure 5B), the gas data that passed the leaching control test (see Figure S4 for details) (orange on Figure 5B) and gave priority to gas measurements replicates in agreement with available graphite measurements (green on Figure 5B). Interestingly, graphite pairs of ${ }^{14} \mathrm{C}$ $\mathrm{B}-\mathrm{P}$ ages correspond to the average of the replicated gas ${ }^{14} \mathrm{C} \mathrm{B}-\mathrm{P}$ ages except for one depth $(35 \mathrm{~cm}, 10.1 \mathrm{ka})$ where the graphite pair ${ }^{14} \mathrm{C} \mathrm{B}-\mathrm{P}$ age is completely offset compared to the gas measurements. This can be related to the sample size requirement of each measurement: because the graphite analysis requires more material, the sampled individuals ( $\mathrm{n}>100$ shells) are more likely to statistically represent the average of the analyzed level 
than the gas samples ( $\mathrm{n}<50$ shells) (Lougheed et al. 2018). We observe that the screened ${ }^{14} \mathrm{C}$ $\mathrm{B}-\mathrm{P}$ ages record obtained by discarding potentially altered measurements and averaging the replicated ${ }^{14} \mathrm{C}$ B-P ages for each level, contain less negative ${ }^{14} \mathrm{C}$ B-P ages (Figure 5B). Thus, it seems very important to adapt the ${ }^{14} \mathrm{C}$ measurement technique according to the study objectives (e.g. average signal or insights in sample heterogeneity) and of course the material availability. Interestingly such sample heterogeneity was not highlighted in existing benthic and planktonic stable isotope records (e.g. Vidal et al. 1997) though they also require a small number of picked and analyzed individuals (in the present case, $\mathrm{n}=30$ for planktonic isotopes and $\mathrm{n}=1$ to 4 for benthic isotopes). This can be mostly attributed to the fact that Holocene stable isotopes have similar values throughout the Holocene period, minimizing the effect of post depositional mixing (bioturbation). Additionally, as proposed by Lougheed et al. (2018), this can be attributed to the nonlinear relationship between ${ }^{14} \mathrm{C}$ activity and ${ }^{14} \mathrm{C}$ age. In fact, the addition of a relatively small amount of ${ }^{14} \mathrm{C}$ young material significantly shifts the final ${ }^{14} \mathrm{C}$ age toward a younger value compared to the actual average ${ }^{14} \mathrm{C}$ age of the sample. Therefore, our study confirms that ${ }^{14} \mathrm{C}$ measurements, and particularly measurements of small-sized samples, offer some insights into deep sea sediment heterogeneity and mixing (Costa et al. 2017; Lougheed et al. 2018).

\section{Consistent Evidence for a Marked Ventilation Change during the Last Deglaciation}

Beyond ${ }^{14} \mathrm{C}$, other proxy measurements may also be used to inform on past bottom water "ventilation," in particular where these relate to deep-water oxygenation. In the modern ocean, a tight relationship is observed between apparent oxygen utilization and the $\delta^{13} \mathrm{C}$ signature of dissolved inorganic carbon (Eide et al. 2017), providing the basis of the use of the benthic $\delta^{13} \mathrm{C}$ as an indirect "paleoventilation" proxy (Duplessy et al. 1988). More recently, it has also been suggested that the REE composition of early diagenetic surface enrichments of planktonic foraminifera can be used to inform on past changes in the oxygen supply to sediments from seawater (Boiteau et al. 2012; Skinner et al. 2019). In oxic seawater, Ce will be present in the less soluble + IV oxidation state, unlike its neighboring trivalent $\mathrm{REE}, \mathrm{La}$ and $\mathrm{Nd}$, resulting in the loss of $\mathrm{Ce}$ from the water column and a characteristic Ce depletion (or "Ce anomaly"). Despite early hopes that the special behavior of $\mathrm{Ce}$ might lend itself to the use of Ce-anomalies in marine sediments as a proxy for past water oxygenation (Liu et al. 1988; German and Elderfield 1990), it appears that REE signatures preserved in marine sediments, for example in early diagenetic surface enrichments on foraminifera, record a significant pore-water influence (German and Elderfield 1990; Skinner et al. 2019). While this would preclude their use as direct indicators of seawater composition, it has been argued that oxygen supply to sediments from seawater could nonetheless still influence the progressive "erosion" of Ce-anomalies recorded in foraminifer surface enrichments (Skinner et al. 2019), producing a Ce-enrichment (relative to an expected seawater depletion), analogous to authigenic Uranium enrichment under low oxygen conditions (Klinkhammer and Palmer 1991; Boiteau et al. 2012).

In this section we compare additional oxygenation-related proxies (i.e. SU90-08 benthic $\delta^{13} \mathrm{C}$-text S3, and Ce enrichments-text S1, as well as authigenic U (Missiaen et al. 2018) to SU90-08 ${ }^{14} \mathrm{C}$ B-P record (Figure 6). Interestingly, all of the records display a relatively synchronous and marked change at the end of HS1 and suggest an increased bottom water oxygenation and ventilation during the Holocene compared to the last glacial period (Figure 6). Late Holocene $\delta^{13} \mathrm{C}$ values are consistent with the well oxygenated and ventilated Labrador Sea Water mixed with the lower North Atlantic Deep water bathing 


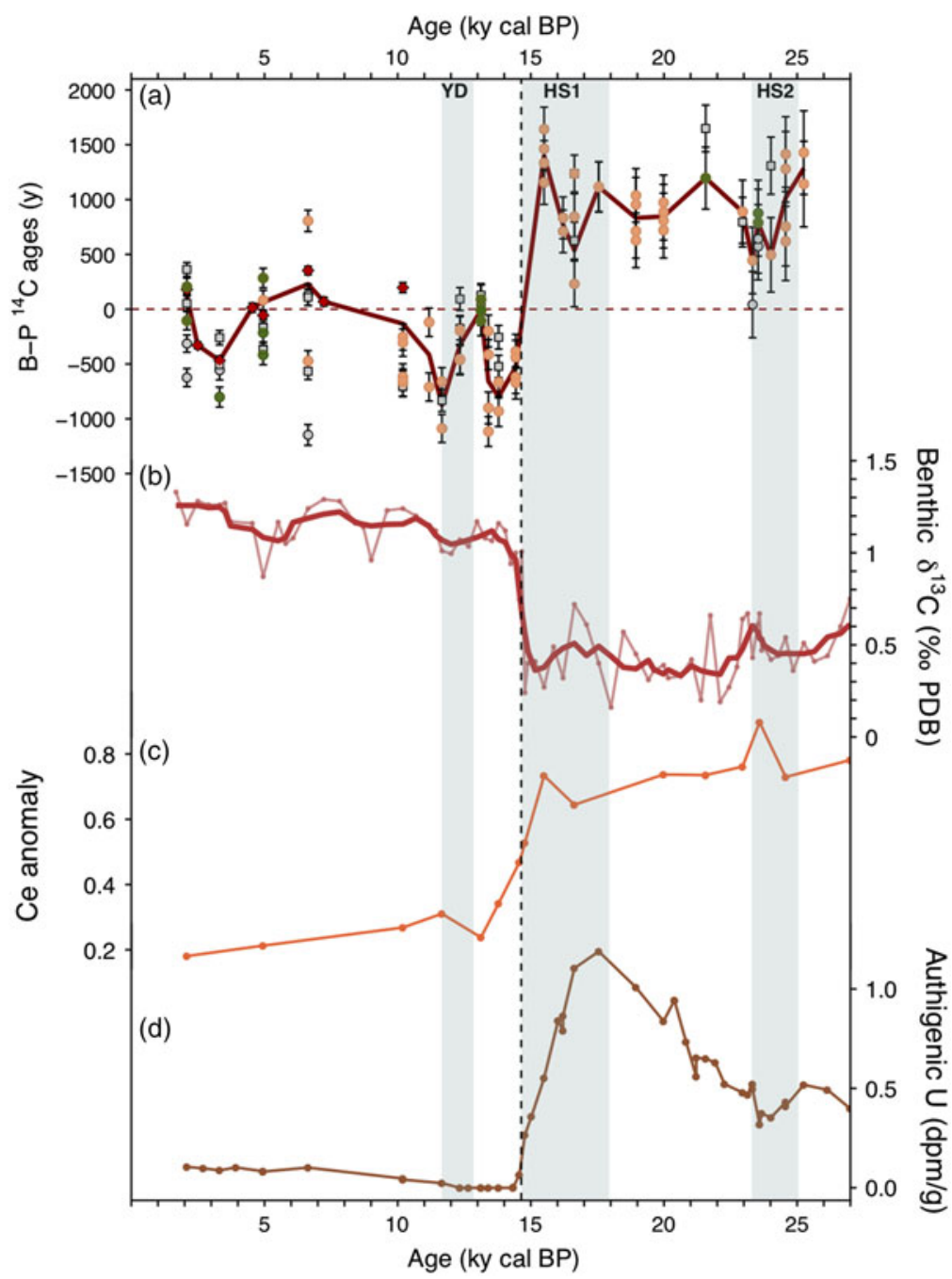

Figure 6 Ventilation and oxygenation time series for SU90-08: (a) B-P ${ }^{14} \mathrm{C}$ ages (as in Figure 3). (b) Benthic $\delta^{13} \mathrm{C}$. The light red line and dots represent the raw data the bold red line represents smoothed data (running average with 5 points). (c) Ce anomaly. (d) Authigenic U calculated after Missiaen et al. (2018). The vertical bands indicate the millennial scale events (YD, HS1, and HS2). The vertical black dashed line highlights the marked ventilation and oxygenation transition at the end of HS1. Age model from Missiaen et al. (2019).

SU90-08 location (Paillet et al. 1998). Finally, glacial ${ }^{14} \mathrm{C}$ B-P ages indicate an increase of the age gradient between the deep and surface waters with respect to the Holocene.

The tentative oxygenation and ventilation history inferred for this site can help explain the reported negative ${ }^{14} \mathrm{C}$ B-P ages. Indeed, under modern, and by extension Holocene conditions, the ${ }^{14} \mathrm{C}$ age gradient between the surface and deep waters is less than 300 years (Key et al. 2004). This reduced ${ }^{14} \mathrm{C}$ age difference is hardly observable in the fossil record because it is very close to the propagated uncertainty of ${ }^{14} \mathrm{C}$ B-P ages. This is particularly 

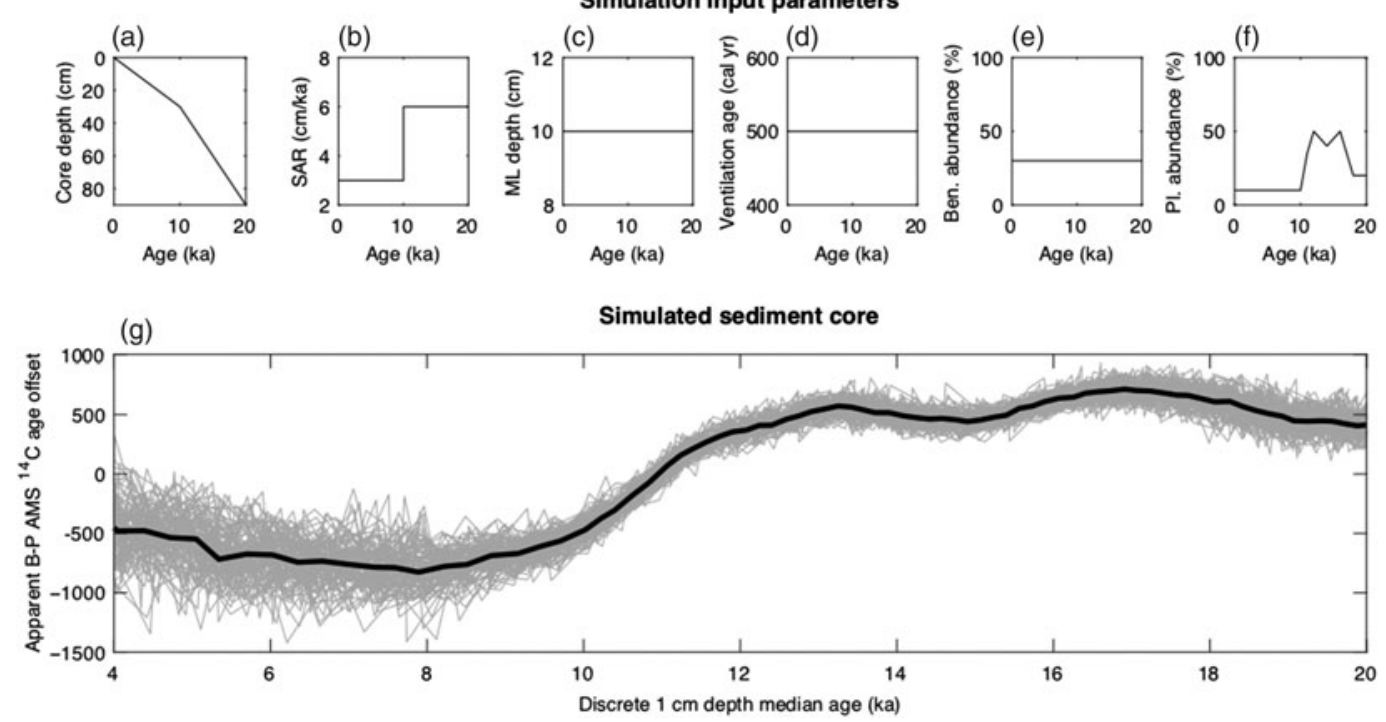

Figure 7 Simulated B-P ${ }^{14} \mathrm{C}$ ages with constant ventilation age but changing foraminifer abundances and sedimentation rate. Single foraminifera sediment simulation with 10 -year timesteps and $10^{4}$ single foraminifera per $\mathrm{cm}$ (simulated using SEAMUS bioturbation model, Lougheed 2020) with constant mixed layer depth $(10 \mathrm{~cm})$ and ventilation age (500 years). At each timestep $n$ new foraminifera are deposited ( $n$ scaled to the sedimentation accumulation rate of the timestep) and assigned a depth according to the input age-depth model. Each foraminifer is assigned a species type (in this case simply planktonic, benthic or other) according to the input abundance for the timestep. ${ }^{14} \mathrm{C}$ activity for each timestep is determined using Marine13), with a timestep ventilation age in the case of benthic foraminifera. At each timestep, depth values in the uppermost depth (mixed layer depth $10 \mathrm{~cm}$ ) are uniformly mixed using random sampling of the mixed depth interval. After the end of the simulation, discrete depth benthic and planktonic expected ages are calculated by taking the mean ${ }^{14} \mathrm{C}$ activity of the benthic and planktonic foraminifera for each discrete depth.

true for gas measurements for which the Holocene average $1 \sigma$ uncertainty is $80 \mathrm{yr}$ for both benthic and planktonic measurements leading to a propagated $1 \sigma$ uncertainty on a gas pair of ${ }^{14} \mathrm{C}$ B-P ages of about $110 \mathrm{yr}$. For comparison, the propagated uncertainty on a graphite pair of ${ }^{14} \mathrm{C}$ B-P ages is around $60 \mathrm{yr}$. Second, the oxygenation and ventilation history is very likely to influence the bioturbation level of the sediment core. Indeed, it appears logical that more benthic fauna might have developed during high oxygenation periods, thus potentially enhancing sediment bioturbation, as suggested by modern observations (e.g. Diaz and Rosenberg 1995; Sturdivant et al. 2012).

\section{Producing Negative ${ }^{14} \mathrm{C}$ B-P Ages Using a Simulation of Bioturbated Sediment}

To further explore the potential of bioturbation to produce the negative ${ }^{14} \mathrm{C} B-\mathrm{P}$ ages observed after HS1 on SU90-08 record, we created an idealized single foraminifera sediment archive simulation, using a single foraminifera sedimentation model developed by (Lougheed 2020). In order to construct an idealized modeling environment whereby as many variables as possible are kept constant, we considered a simple scenario with constant true ventilation ages and a uniform sediment mixed layer depth of $10 \mathrm{~cm}$ as well as idealized benthic and planktonic foraminifer abundances (Figure 7), so that we may use the model to quantify the influence of an isolated change in a single variable. The simulation only considers one class (species) of planktonic foraminifers and one class (mixed species) of benthic foraminifers. Also, we do not consider millennial scale variability in the input planktonic 
foraminifer abundance evolution, and simply assume higher abundances during the glacial period compared to the Holocene.

This is generally consistent with the broad evolution of G. bulloides abundances in SU90-08 (Figure 1) but intentionally does not mimic the full complexity of observed planktonic abundance. Because of the absence of benthic abundance record and because this is an idealized experiment, we chose to consider a constant benthic abundance. With those simplified settings, we show that it is possible to produce negative ${ }^{14} \mathrm{C} \mathrm{B}-\mathrm{P}$ ages for the younger periods. Decreased abundance of planktonic species during younger periods compared to older periods (pre-HS1), combined with bioturbation, lead to a bias of planktonic ${ }^{14} \mathrm{C}$ ages towards older ${ }^{14} \mathrm{C}$ ages for younger periods, the bioturbation moving upward material from high abundance peaks lower down in the core. Subsequently, if the abundance histories of benthic and planktonic foraminifera are out of phase or significantly different (as shown here), erroneous ${ }^{14} \mathrm{C}$ B-P ages can be produced. This is consistent with earlier studies such as Peng and Broecker (1984); Wu and Hillaire-Marcel (1994). In addition, the dynamic ${ }^{14} \mathrm{C}$ history of the atmosphere, combined with the delay necessary for ${ }^{14} \mathrm{C}$ activity to reach the deep ocean, can also lead to dynamics in ${ }^{14} \mathrm{C}$ B-P ages that are not necessarily related to ocean ventilation (e.g. Adkins 1997; Lund et al. 2011).

\section{CONCLUSIONS}

We have performed ${ }^{14} \mathrm{C}$ measurements on benthic and planktonic foraminifers from deep sea sediment core SU90-08 using gas introduction system and MICADAS setup. This experimental setting allows the analysis of small-sized samples making high-resolution ${ }^{14} \mathrm{C}$ measurements possible for cores with low foraminifer content. Besides, the use of the gas introduction system reduces the samples preparation time and the contamination risk as it omits the graphitization step. Additionally, the analysis of the ${ }^{14} \mathrm{C}$ content of the leach fraction corresponding to the outer foraminifer shell can bring valuable information about the dissolution/recrystallization state of the analyzed material.

We have shown that the measurements obtained were accurate and that the precision was only slightly decreased compared to conventional graphite AMS measurements. The reproducibility of the gas MICADAS measurements is generally satisfactory and highly dependent on the analyzed foraminifer material. Our gas measurements generally agree with conventional graphite measurements within $2 \sigma$ uncertainty and graphite measurements yield values close to the average of the two gas replicates.

From this ${ }^{14} \mathrm{C}$ dataset we calculated ensembles of ${ }^{14} \mathrm{C}$ B-P ages for each considered sediment level and obtained reproducible negative ${ }^{14} \mathrm{C}$ B-P ages in the post $\mathrm{HS} 1$ part of the record. We showed that those negative ${ }^{14} \mathrm{C}$ B-P ages unlikely reflect a hydrothermal imprint on ${ }^{14} \mathrm{C}$ content or the effect of the dissolution and recrystallization of the foraminifer shells. Instead, we argue that small-sized ${ }^{14} \mathrm{C}$ analysis highlights the heterogeneity of the foraminifer material contained in a single sediment level, particularly under conditions of relatively low sediment accumulation. We argue that these negative ${ }^{14} \mathrm{C}$ B-P ages actually reflect potential core bioturbation in a context of very low ${ }^{14} \mathrm{C}$ age gradient between the surface and deep waters. Indeed, additional/auxiliary ventilation and oxygenation proxies derived from benthic $\delta^{13} \mathrm{C}$ and $\mathrm{Ce}$ anomalies in authigenic foraminifer coatings indicate that poorly ventilated and less oxygenated deep-water bathed the site until the end of HS1. After this, well-ventilated and oxygenated deep-water, likely originating in part from the Labrador 
Sea, bathed the site as under modern conditions. This ventilation and oxygenation history is consistent with enhanced bioturbation after HS1. Consequently, established understanding of bioturbation, combined with dynamic changes in benthic and planktonic foraminiferal abundances, help to explain the existence of negative ${ }^{14} \mathrm{C}$ B-P ages, as we show using a single foraminifera simulation (Lougheed 2020).

Therefore, it appears that the main limitation for small-sized gas ${ }^{14} \mathrm{C}$ analysis stems not from the method, but from the syn- and post-depositional history of the sedimentary material that is analyzed. More so than conventional stable isotopes, replicated small-sized ${ }^{14} \mathrm{C}$ measurements appear to reveal the heterogeneity of the material contained in a sediment level. There are two major reasons for this: (i) the replication of small-sized analysis gives insight into the distribution of the ${ }^{14} \mathrm{C}$ age of the sediment level content, and (ii) ${ }^{14} \mathrm{C}$ activity has an exponential relation with time, which makes it even more sensitive to mixing of differently aged components. This case study highlights that the uncertainty on ${ }^{14} \mathrm{C}$ measurements that derives from machine error propagation can often be much smaller than the noise/ uncertainty related to the sedimentation history. Special care should therefore be taken when interpreting small variations in ${ }^{14} \mathrm{C}$ B-P age offsets, as they could reflect the impacts of bioturbation, dissolution/recrystallization, or just changes in atmospheric ${ }^{14} \mathrm{C}$ composition, rather than ocean ventilation changes.

\section{ACKNOWLEDGMENTS}

This is a contribution to ERC project ACCLIMATE; the research leading to these results has received funding from the European Research Council under the European Union's Seventh Framework Programme (FP7/2007-2013)/ERC grant agreement 339108. LM acknowledges funding from the Australian Research Council grant DP180100048. BCL acknowledges Swedish Research Council (Vetenskapsrådet - VR) Starting Grant number 2018-04992. LCS acknowledges support from NERC grant NE/L006421/1. We thank E. Michel for fruitful discussion and $\mathrm{S}$. Moreira for his help with $\mathrm{R}$ programming. This is LSCE contribution 6963. The authors declare that they have no conflicts of interest. The data will be available online on Pangaea database (https://www.pangaea.de/).

\section{SUPPLEMENTARY MATERIAL}

To view supplementary material for this article, please visit https://doi.org/10.1017/RDC. 2020.13

\section{REFERENCES}

Adkins JF. 1997. Changing atmospheric $\delta^{14} \mathrm{C}$ and the record of deep water paleoventilation ages. Paleoceanography 12(3):337-344.

Adkins JF, Cheng H, Boyle EA, Druffel ERM, Edwards RL. 1998. Deep-sea coral evidence for rapid change in ventilation of the deep North Atlantic 15,400 years ago. Science 280(5364): 725-728.

Bard E, Tuna T, Fagault Y, Bonvalot L, Wacker L, Fahrni S, Synal H-A. 2015. AixMICADAS, the accelerator mass spectrometer dedicated to ${ }^{14} \mathrm{C}$ recently installed in Aix-en-Provence, France. Nuclear Instruments and Methods in Physics

Research Section B: Beam Interactions with Materials and Atoms 361:80-86.

Barker S, Broecker W, Clark E, Hajdas I. 2007. Radiocarbon age offsets of foraminifera resulting from differential dissolution and fragmentation within the sedimentary bioturbated zone. Paleoceanography 22(2).

Berger WH, Heath GR. 1968. Vertical mixing in pelagic sediments. J Mar Res. 26:134-143.

Berger WH, Johnson RF. 1978. On the thickness and the ${ }^{14} \mathrm{C}$ age of the mixed layer in deep-sea carbonates. Earth and Planetary Science Letters 41(2):223-227. 
Berger WH, Killingley JS. 1982. Box cores from the equatorial pacific: ${ }^{14} \mathrm{C}$ sedimentation rates and benthic mixing. Marine Geology 45(1):93-125.

Boiteau R, Greaves M, Elderfield H. 2012. Authigenic uranium in foraminiferal coatings: A proxy for ocean redox chemistry. Paleoceanography 27(3).

Bout-Roumazeilles V, Cortijo E, Labeyrie L, Debrabant P. 1999. Clay mineral evidence of nepheloid layer contributions to the Heinrich layers in the northwest Atlantic. Palaeogeography, Palaeoclimatology, Palaeoecology 146(1):211-228.

Broecker W, Mix A, Andree M, Oeschger H. 1984. Radiocarbon measurements on coexisting benthic and planktic foraminifera shells: Potential for reconstructing ocean ventilation times over the past 20000 years. Nuclear Instruments and Methods in Physics Research Section B: Beam Interactions with Materials and Atoms 5(2):331-339.

Broecker WS, Andree M, Bonani G, Wolfli W, Klas M, Mix A, Oeschger H. 1988. Comparison between radiocarbon ages obtained on coexisting planktonic foraminifera. Paleoceanography 3(6): 647-657.

Broecker WS, Bond G, Klas M, Bonani G, Wolfli W. 1990. A salt oscillator in the glacial Atlantic? 1. The concept. Paleoceanography 5(4):469-477.

Chen T, Robinson LF, Burke A, Southon J, Spooner P, Morris PJ, Ng HC. 2015. Synchronous centennial abrupt events in the ocean and atmosphere during the last deglaciation. Science 349(6255):1537.

Costa KM, McManus JF, Anderson RF. 2017. Radiocarbon and stable isotope evidence for changes in sediment mixing in the north pacific over the past 30 kyrr. Radiocarbon 1-23.

Diaz RJ, Rosenberg R. 1995. Marine benthic hypoxia: A review of its ecological effects and the behavioural responses of benthic macrofauna. Oceanography and Marine Biology: An annual Review 33:245-203.

Duplessy JC, Shackleton NJ, Fairbanks RG, Labeyrie L, Oppo D, Kallel N. 1988. Deepwater source variations during the last climatic cycle and their impact on the global deepwater circulation. Paleoceanography 3(3):343-360.

Eide M, Olsen A, Ninnemann US, Johannessen T. 2017. A global ocean climatology of preindustrial and modern ocean $\delta^{13} \mathrm{C}$. Global Biogeochemical Cycles 31(3):515-534.

Freeman E, Skinner LC, Reimer R, Scrivner A, Fallon S. 2016. Graphitization of small carbonate samples for paleoceanographic research at the Godwin radiocarbon laboratory, University of Cambridge. Radiocarbon 58(1):89-97.

Gao P, Xu X, Zhou L, Pack MA, Griffin S, Santos GM, Southon JR, Liu K. 2014. Rapid sample preparation of dissolved inorganic carbon in natural waters using a headspace-extraction approach for radiocarbon analysis by accelerator mass spectrometry. Limnology and Oceanography: Methods 12(4):174-190.

German CR, Elderfield H. 1990. Application of the $\mathrm{CE}$ anomaly as a paleoredox indicator: The ground rules. Paleoceanography 5(5):823-833.

Gottschalk J, Szidat S, Michel E, Mazaud A, Salazar G, Battaglia M, Lippold J, Jaccard SL. 2018. Radiocarbon measurements of small-size foraminiferal samples with the mini carbon dating system (MICADAS) at the University of Bern: Implications for paleoclimate reconstructions. Radiocarbon 60(2):469-491.

Grousset FE, Labeyrie L, Sinko JA, Cremer M, Bond G, Duprat J, Cortijo E, Huon S. 1993. Patterns of ice-rafted detritus in the glacial North Atlantic (40-55 n). Paleoceanography 8(2):175-192.

Guinasso NL, Schink DR. 1975. Quantitative estimates of biological mixing rates in abyssal sediments. Journal of Geophysical Research 80(21):3032-3043.

Key RM, Kozyr A, Sabine CL, Lee K, Wanninkhof R, Bullister JL, Feely RA, Millero FJ, Mordy C, Peng TH. 2004. A global ocean carbon climatology: Results from global data analysis project (GLODAP). Global Biogeochemical Cycles 18(4).

Kissel C. 2005. Magnetic signature of rapid climatic variations in glacial North Atlantic, a review. Comptes Rendus Geoscience 337(10):908-918.

Klinkhammer GP, Palmer MR. 1991. Uranium in the oceans: Where it goes and why. Geochimica et Cosmochimica Acta 55(7):1799-1806.

Le J, Shackleton NJ. 1992. Carbonate dissolution fluctuations in the western equatorial pacific during the late quaternary. Paleoceanography 7(1):21-42.

Liu YG, Miah MRU, Schmitt RA. 1988. Cerium: A chemical tracer for paleo-oceanic redox conditions. Geochimica et Cosmochimica Acta 52(6):1361-1371.

Lougheed BC. 2020. Seamus (v1.0): A $\delta^{14}$ C-enabled, single-specimen sediment accumulation simulator. Geosci Model Dev. 2020:1-28.

Lougheed BC, Metcalfe B, Ninnemann US, Wacker L. 2018. Moving beyond the age-depth model paradigm in deep-sea palaeoclimate archives: Dual radiocarbon and stable isotope analysis on single foraminifera. Climate of the Past 14(4): 515-526.

Lougheed BC, Snowball I, Moros M, Kabel K, Muscheler R, Virtasalo JJ, Wacker L. 2012. Using an independent geochronology based on palaeomagnetic secular variation (psv) and atmospheric $\mathrm{pb}$ deposition to date baltic sea sediments and infer ${ }^{14} \mathrm{C}$ reservoir age. Quaternary Science Reviews 42:43-58.

Lund DC, Mix AC, Southon J. 2011. Increased ventilation age of the deep northeast Pacific Ocean during the last deglaciation. Nature Geoscience 4(11):771. 
Magana AL, Southon JR, Kennett JP, Roark EB, Sarnthein M, Stott LD. 2010. Resolving the cause of large differences between deglacial benthic foraminifera radiocarbon measurements in Santa Barbara Basin. Paleoceanography 25(4).

Marchig V, Möller P, Bäcker H, Dulski P. 1984. Foraminiferal ooze from the galapagos rift area-hydrothermal impact and diagenetic mobilization of elements. Marine Geology 62(1): 85-104.

McCarthy MD, Beaupré SR, Walker BD, Voparil I, Guilderson TP, Druffel ERM. 2011. Chemosynthetic origin of ${ }^{14} \mathrm{C}$-depleted dissolved organic matter in a ridge-flank hydrothermal system. Nature Geoscience 4(1):32-36.

Mekik F. 2014. Radiocarbon dating of planktonic foraminifer shells: A cautionary tale. Paleoceanography 29(1):13-29.

Missiaen L, Pichat S, Waelbroeck C, Douville E, Bordier L, Dapoigny A, Thil F, Foliot L, Wacker L. 2018. Downcore variations of sedimentary detrital $\left({ }^{238} \mathrm{U} /{ }^{232} \mathrm{Th}\right)$ ratio: Implications on the use of 230thxs and 231paxs to reconstruct sediment flux and ocean circulation. Geochemistry, Geophysics, Geosystems 0(ja).

Missiaen L, Waelbroeck C, Pichat S, Jaccard SL, Eynaud F, Greenop R, Burke A. 2019. Improving North Atlantic marine core chronologies using ${ }^{232}$ Th-normalization. Paleoceanography and Paleoclimatology 0(ja).

Muscheler R, Beer J, Kubik PW, Synal HA. 2005. Geomagnetic field intensity during the last 60,000 years based on ${ }^{10} \mathrm{Be}$ and ${ }^{36} \mathrm{Cl}$ from the summit ice cores and ${ }^{14} \mathrm{C}$. Quaternary Science Reviews 24(16-17):1849-1860.

Muscheler R, Beer J, Wagner G, Laj C, Kissel C, Raisbeck GM, Yiou F, Kubik PW. 2004. Changes in the carbon cycle during the last deglaciation as indicated by the comparison of ${ }^{10} \mathrm{Be}$ and ${ }^{14} \mathrm{C}$ records. Earth and Planetary Science Letters 219(3-4):325-340.

Paillet J, Arhan M, McCartney MS. 1998. Spreading of labrador sea water in the eastern North Atlantic. Journal of Geophysical Research: Oceans 103(C5):10223-10239.

Peng T-H, Broecker WS. 1984. The impacts of bioturbation on the age difference between benthic and planktonic foraminifera in deep sea sediments. Nuclear Instruments and Methods in Physics Research Section B: Beam Interactions with Materials and Atoms 5(2):346-352.

Peng TH, Broecker WS, Berger WH. 1997. Rates of benthic mixing in deep-sea sediment as determined by radioactive tracers. Quaternary Research 11(1):141-149.

Rafter PA, Herguera JC, Southon JR. 2018. Extreme lowering of deglacial seawater radiocarbon recorded by both epifaunal and infaunal benthic foraminifera in a wood-dated sediment core. Clim. Past 14(12):1977-1989.
Reimer PJ, Bard E, Bayliss A, Beck JW, Blackwell PG, Ramsey CB, Buck CE, Cheng H, Edwards RL, Friedrich M. 2013. IntCal13 and Marine13 radiocarbon age calibration curves $0-50,000$ years cal BP. Radiocarbon 55(4):1869-1887.

Robinson LF, Adkins JF, Keigwin LD, Southon J, Fernandez DP, Wang SL, Scheirer DS. 2005. Radiocarbon variability in the western North Atlantic during the last deglaciation. Science 310(5753):1469-1473.

Rozanski K, Stichler W, Gonfiantini R, Scott EM, Beukens RP, Kromer B, van der Plicht J. 1992. The IAEA ${ }^{14} \mathrm{C}$ intercomparison exercise 1990. Radiocarbon 34(3):506-519.

Santos GM, Southon JR, Griffin S, Beaupre SR, Druffel ERM. 2007. Ultra small-mass ams ${ }^{14} \mathrm{C}$ sample preparation and analyses at KCCAMS/ UCI facility. Nuclear Instruments and Methods in Physics Research Section B: Beam Interactions with Materials and Atoms 259(1): 293-302.

Shah Walter SR, Gagnon AR, Roberts ML, McNichol AP, Gaylord MCL, Klein E. 2016. Ultra-small graphitization reactors for ultramicroscale ${ }^{14} \mathrm{C}$ analysis at the National Ocean Sciences Accelerator Mass Spectrometry (NOSAMS) facility. Radiocarbon 57(1):109-122.

Skinner LC, Sadekov A, Brandon M, Greaves M, Plancherel Y, de La Fuente M, Gottschalk J, Souanef-Ureta S, Sevilgen DS, Scrivner AE. 2019. Rare earth elements in early-diagenetic foraminifer 'coatings': Pore-water controls and potential palaeoceanographic applications. Geochimica et Cosmochimica Acta 245:118-132.

Skinner LC, Shackleton NJ. 2004. Rapid transient changes in northeast Atlantic deep water ventilation age across termination i. Paleoceanography 19(2).

Skinner LC, Waelbroeck C, Scrivner AE, Fallon SJ. 2014. Radiocarbon evidence for alternating northern and southern sources of ventilation of the deep Atlantic carbon pool during the last deglaciation. Proceedings of the National Academy of Sciences.

Soulet G, Skinner LC, Beaupré SR, Galy V. 2016. A note on reporting of reservoir ${ }^{14} \mathrm{C}$ disequilibria and age offsets. Radiocarbon 58(1):205-211.

Sturdivant SK, Díaz RJ, Cutter GR. 2012. Bioturbation in a declining oxygen environment, in situ observations from wormcam. PloS one 7(4):e34539.

Synal H-A, Stocker M, Suter M. 2007. MICADAS: A new compact radiocarbon ams system. Nuclear Instruments and Methods in Physics Research Section B: Beam Interactions with Materials and Atoms 259(1):7-13.

Thornalley DJR, Bauch HA, Gebbie G, Guo W, Ziegler M, Bernasconi SM, Barker S, Skinner LC, Yu J. 2015. A warm and poorly ventilated deep arctic mediterranean during the last glacial period. Science 349(6249):706-710. 
Trauth MH, Sarnthein M, Arnold M. 1997. Bioturbational mixing depth and carbon flux at the seafloor. Paleoceanography 12(3):517-526.

Vidal L, Labeyrie L, Cortijo E, Arnold M, Duplessy JC, Michel E, Becque S, Van Weering TCE. 1997. Evidence for changes in the North Atlantic deep water linked to meltwater surges during the heinrich events. Earth and Planetary Science Letters 146(1):13-27.

Vogel JS, Southon JR, Nelson DE, Brown TA. 1984. Performance of catalytically condensed carbon for use in accelerator mass spectrometry. Nuclear Instruments and Methods in Physics Research Section B: Beam Interactions with Materials and Atoms 5(2):289-293.

Wacker L, Christl M, Synal HA. 2010. Bats: A new tool for AMS data reduction. Nuclear Instruments and Methods in Physics Research Section B: Beam Interactions with Materials and Atoms 268(7):976-979.

Wacker L, Fahrni SM, Hajdas I, Molnar M, Synal HA, Szidat S, Zhang YL. 2013a. A versatile gas interface for routine radiocarbon analysis with a gas ion source. Nuclear Instruments and Methods in
Physics Research Section B: Beam Interactions with Materials and Atoms 294:315-319.

Wacker L, Lippold J, Molnár M, Schulz H. 2013b. Towards radiocarbon dating of single foraminifera with a gas ion source. Nuclear Instruments and Methods in Physics Research Section B: Beam Interactions with Materials and Atoms 294:307-310.

Wan S, Jian Z. 2014. Deep water exchanges between the south china sea and the pacific since the last glacial period. Paleoceanography. 29(12): 1162-1178.

Wu G, Hillaire-Marcel C. 1994. Accelerator mass spectrometry radiocarbon stratigraphies in deep labrador sea cores: Paleoceanographic implications. Canadian Journal of Earth Sciences 31(1):38-47.

Wycech J, Kelly DC, Marcott S. 2016. Effects of seafloor diagenesis on planktic foraminiferal radiocarbon ages. Geology 44(7):551-554.

Yu J, Elderfield H. 2007. Benthic foraminiferal b/ca ratios reflect deep water carbonate saturation state. Earth and Planetary Science Letters 258(1): 73-86. 